\title{
APLIKASI INTERNET OF THINGS MONITORING SUHU ENGINE UNTUK MENCEGAH TERJADINYA OVER HEAT
}

\author{
Randis ${ }^{1}$, Sarminto ${ }^{2}$ \\ Jurusan Teknik Mesin, Program Studi Alat Berat, Politeknik Negeri Balikpapan ${ }^{1,2}$ \\ JI. Soekarno Hatta Km. 8, Balikpapan, Kalimantan Timur \\ e-mail ; randis@poltekba.co.id ${ }^{1}$, sarmintotmab3tm1@gmail.com²
}

\begin{abstract}
Abstrak
Tujuan dari penelitian ini untuk mendesain dan membuat sistem online monitoring temperatur engine berbasis Internet of Things (IoT). Sistem ini didesain dan dikembangkan untuk memantau temperatur engine baik melalui website thingspeak dan aplikasi android virtuino. Sistem terdiri dari beberapa komponen, komponen utama yaitu arduino uno yang akan memperoleh sinyal input dari sensor temperatur DS18B20, setelah itu data disimpan di database menggunakan jaringan internet melalui wifi. Peningkatan temperatur ketika engine beroperasi direkam oleh sensor dan akan dikirim ke mikrokontroller yang dapat diakses melalui website ataupun perangkat mobile. Hasil percobaan menunjukkan bahwa selisih nilai pembacaan sensor dengan alat ukur yang terkalibrasi cukup kecil yaitu hanya sebesar $0,14^{\circ} \mathrm{C}$, sedangkan margin error diperoleh 0,14\%. Pengujian alat dilakukan dengan menjalankan engine dengan rentang waktu 1 jam, dan diperoleh temperatur tertinggi engine sebesar $69^{\circ} \mathrm{C}$ dan dapat diakses dengan website dan aplikasi pada perangkat mobile.
\end{abstract}

Kata kunci: Engine, Internet of Things (loT), Temperature, Thingspeak, Virtuino.

\section{PENDAHULUAN}

Perusahaan kontraktor tambang internasional memiliki target produksi yang sangatlah besar, seluruh kegiatan perusahaan difokuskan terutama pada kegiatan penambangan dan pengelolaan material tambang seperti batu bara. Di dalam kegiatan produksi penambangan secara umum dibagi menjadi 3 kegiatan pokok pembiayaan (mining value chain), yaitu:

1. Extraction, meliputi drilling, blasting, loading, hauling dan dumping,

2. Refining, crushing, milling dan processing,

3. General, mining overheat, deprectation dan corporate overheat [1].

Menurut data dari PT. United Tractors, Cabang Tarakan Site Sesayap pada tahun 2017 laju pertumbuhan unit alat berat di Kalimantan Utara makin meningkat, tercatat populasi unit alat berat di Site Seayap meningkat mencapai 295 unit, dan diperkirakan jumlah unit tersebut akan mengalami peningkatan seiring dengan bertambahnya produksi batu bara yang ada di site tersebut. Data perusahaan menunjukkan bahwa terjadi kerusakan pada berbagai jenis unit alat berat, dimana unit excavator menyumbang sekitar $15 \%$ yang mengalami overheat, kerugian diperkirakan mencapai hingga milliyaran rupiah, tentu nilai ini cukup besar apabila nilai ini diproporsionalkan dengan pendapatan perusahaan (revenue) [2].

$\begin{array}{ccc} & \text { Overheating merupakan suatu } \\ \text { kondisi dimana temperatur mesin }\end{array}$ kendaraan melebihi batas normal. Menjaga keadaan temperatur mesin agar tetap pada batas normal sangat penting dilakukan untuk menghindari kerusakan fatal pada komponen mesin jika kendaraan mengalami overheating [3]. Overheat yang terjadi pada mesin akan mengakibatkan panas yang berlebih pada mesin sehingga menimbulkan kerusakan pada beberapa komponen mesin [4]. 
Internet of Things merupakan perangkat komunikasi antar suatu objek yang dilengkapi dengan mikrocontroller, transceiver untuk komunikasi digital, dan tumpukan protokol yang sesuai yang mampu membuat mereka dapat berkomunikasi satu sama lain dengan pengguna dan terintegrasi dengan internet dengan menyediakan berbagai jenis data yang diinginkan [5]-[6]. Internet of Things menanamkan beberapa kecerdasan dalam objek yang terhubung ke internet untuk berkomunikasi, bertukar informasi, mengambil keputusan, melakukan tindakan dan memberikan layanan yang luar biasa [7].

Penggunaan Internet of Thing telah banyak digunakan di berbagai aplikasi mulai dari smart city, smart home, smart room, smart parking dan aplikasi pada industri [8]-[11]. Sehingga penggunaan sistem Internet of Thing untuk dapat mencegah terjadinya overheat pada mesin dipandang dapat menjadi solusi.

Penelitian sebelumnya menggunakan perangkat Internet of Things untuk memonitor dan mengontrol temperatur dan kelembaban, pada penelitian ini hanya manpu menunjukkan monitoring dalam bentuk data dan belum berupa grafik. Perangkat yang digunakan hanya terbatas pada aplikasi pada smartphone [1]. Penelitian lainnya dengan menggunakan Internet of Things untuk memantau kadar gas pada tempat pembuangan akhir sampah, pada penelitian ini mampu menampilkan grafik yang dapat diakses melalui website, namun belum dilengkapi dengan aplikasi mobile pada perangkat smartphone untuk dapat mengakses data baik berupa grafik atau angka.

Pada penelitian ini dirancang dan dikembangkan sistem monitoring suhu engine berbasis Internet of Things yang dapat dipantau melalui website (Thingspeak) dan melalui perangkat mobile aplikasi android (virtuino) serta penggunaan lampu indikator dan buzzer jika temperatur mesin telah mencapai batas maksimum yang diizinkan untuk mencegah terjadinya overheat pada engine.

\section{METODE PENELITIAN}

\section{Perancangan Sistem Elektrikal}

Perancangan sistem elektrikal ditunjukkan pada Gambar 1. Hal ini merupakan tahapan perencanaan dan desain dari sistem elektrikal yang akan dibuat, dengan perancang dapat dengan mudah membaca alur dari sistem yang digunakan yang berfungsi untuk mengetahui komponen-komponen yang berperan sebagai input, kontroler dan output yang dibutuhkan.

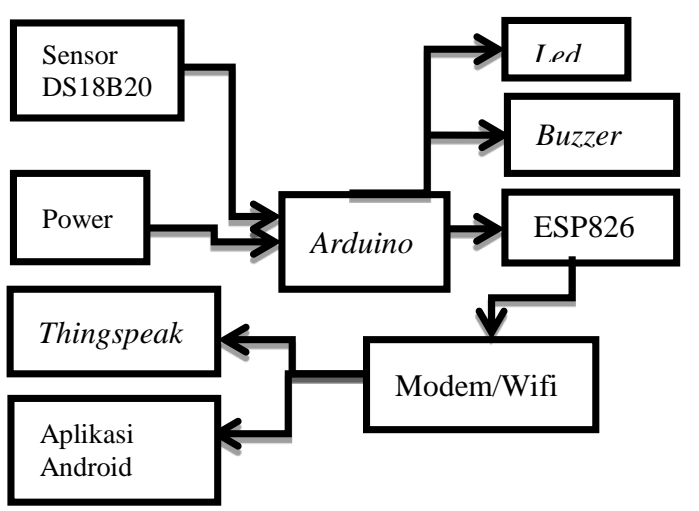

Gambar 1. Perancangan sistem elektrikal

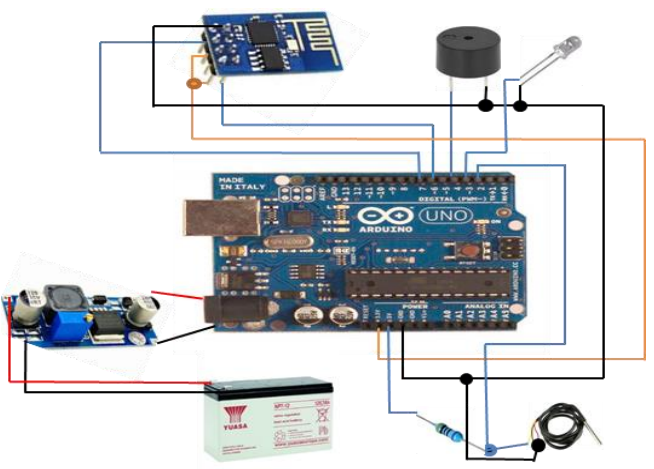

Gambar 2. Imlementasi sistem elektrikal

Pada Gambar 2 menunjukkan implementasi sistem elektrik, arduino bertindak sebagai mikrokontroller yang akan mengolah sinyal yang dikirimkan oleh sensor temperatur DS18B20. Kemudian output berupa grafik dapat dilihat melalui website dan aplikasi android (virtuino) yang sudah tersambung ke internet dengan menggunakan ESP8266. Output berupa indikator lampu LED dan Buzzer untuk menunjukkan pada operator bahwasannya 
unit harus segera dimatikan karena telah terjadi overheat pada mesin.

\section{Perancangan Sistem Mekanik}

Mesin pembakaran dalam atau Internal Combustion Engine merupakan mesin yang sering digunakan pada kendaraan. Kasus yang sering terjadi pada mesin tersebut yaitu panas berlebih atau overheating. Efek yang ditimbulkan dari kasus tersebut ialah kinerja mesin akan mengalami penurunan bahkan mesin akan mati dengan sendirinya [14]. Ini sering dikarenkan cooling sistem pada engine tidak berfungsi dengan baik.

Alat yang dirancang dan dikembangkan berfungsi untuk memonitoring temperatur kerja engine berbasis Internet Of Things. Cara kerjanya yaitu dari sensor mengirmkan data yang akan dibaca oleh arduino dan mengirmkan sebuah output ke modul ESP8266 yang berbentuk database, penempatan sensor temperatur diantara engine dan thermostat.

Pada sistem monitoring temperatur engine berbasis internet of things, sensor diletakkan sebelum thermostat dari ruang bakar guna untuk mendeteksi temperatur coolant sebelum didinginkan oleh radiator dengan bantuan udara dari luar, sensor bekerja ketika alat mendapatkan supply power dari battery dan engine bekerja. Penempatan sensor dan alat pada sistem mekanik diperlihatkan pada Gambar 3.

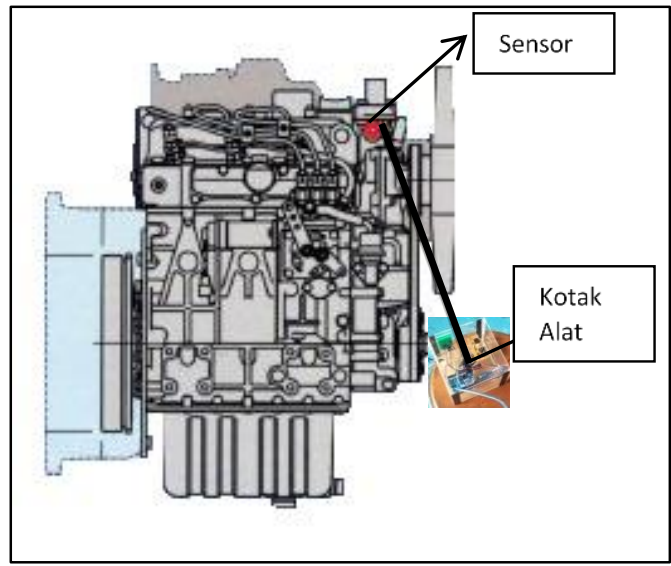

Gambar 3. Sistem Mekanik

\section{Flowchart Prinsip Kerja Alat}

Gambar 4 menunjukkan flowchart prinsip kerja alat monitoring temperatur engine berbasis Internet of Things menggunakan esp8266 ver 01 sebagai penghubung ke jaringan, jika tampilan di serial monitor terhubung maka esp8266 sukses dan jika gagal menghubungkan kembali. Sensor sebagai signal input kemudian data diolah oleh arduino dan dikirim ke internet, jika temperatur terbaca lebih dari $95^{\circ} \mathrm{C}$ maka led dan buzzer akan bekerja dan jika di bawah $95^{\circ} \mathrm{C}$ led dan buzzer tidak bekerja.

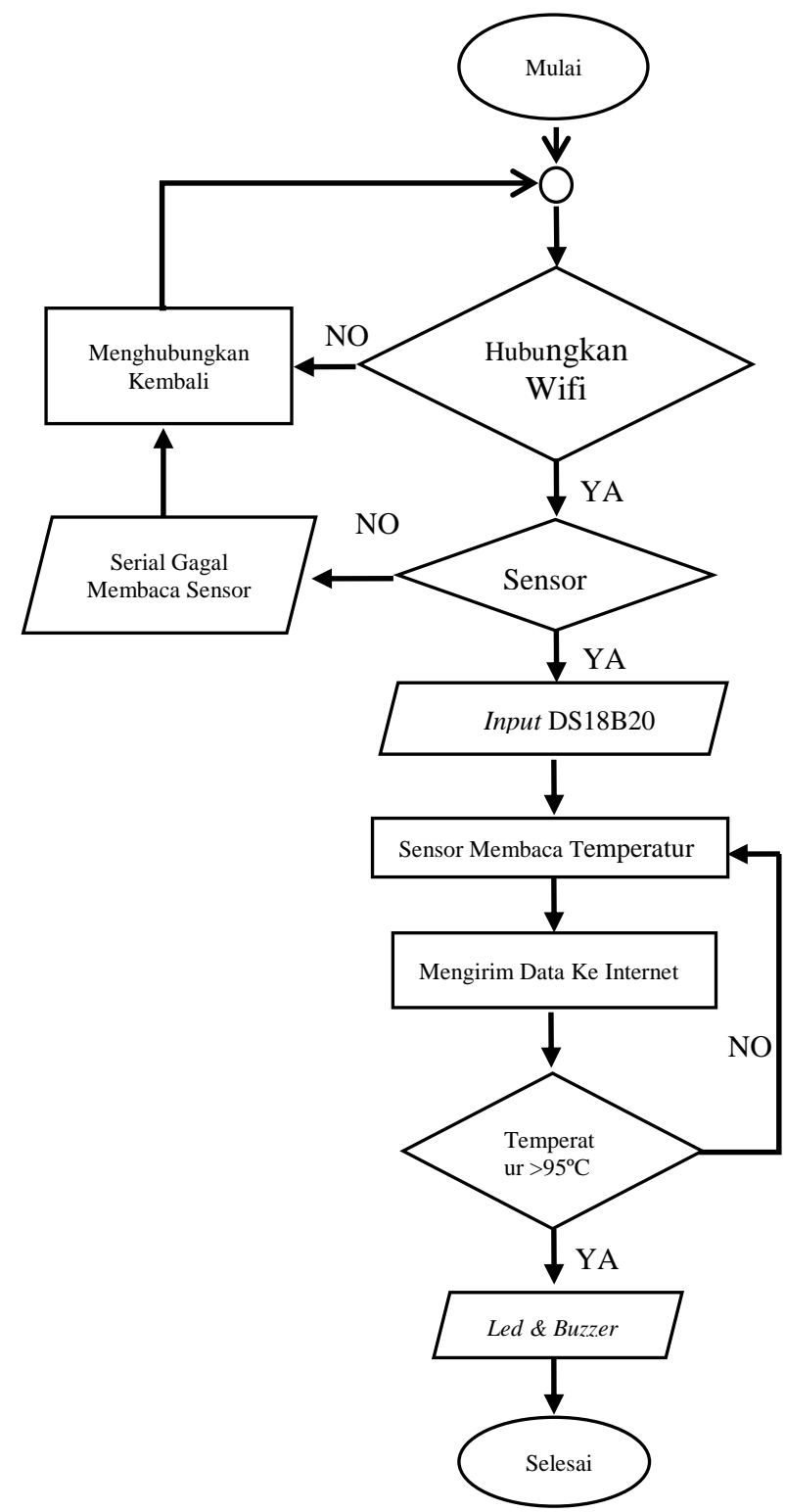

Gambar 4. Flowchart Prinsip Kerja Sistem 


\section{HASIL DAN PEMBAHASAN}

\section{Pengujian Sensor}

Pengujian sensor ini dilakukan untuk mengecek dan memastikan sensor berfungsi atau tidak dengan margin error yang tidak terlalu tinggi. Adapun hasil dari pengujiannya dapat dilihat pada Tabel 1 .

Table 1. Pengujian Keluaran Sensor

\begin{tabular}{|c|c|c|}
\hline No & $\begin{array}{c}\text { Tampilan } \\
\text { Suhu dengan } \\
\text { Sensor } \\
\text { DS18B20 }\end{array}$ & $\begin{array}{c}\text { Tampilan Suhu } \\
\text { dengan alat ukur } \\
\text { Termometer Gun }\end{array}$ \\
\hline 1 & $40.94^{\circ} \mathrm{C}$ & $40.8^{\circ} \mathrm{C}$ \\
\hline 2 & $50^{\circ} \mathrm{C}$ & $49.86^{\circ} \mathrm{C}$ \\
\hline 3 & $52.40^{\circ} \mathrm{C}$ & $51.26^{\circ} \mathrm{C}$ \\
\hline 4 & $60.80^{\circ} \mathrm{C}$ & $59.66^{\circ} \mathrm{C}$ \\
\hline
\end{tabular}

Hasil pengujian di atas dapat dinyatakan bahwa pembacaan sensor sudah akurat, dan sensor tersebut sudah dikalibrasi dengan thermometer selisih pembacaan temperatur sekitar $0.14^{\circ} \mathrm{C}$.

\section{Margine of Error}

Setelah melakukan uji coba pada engine Kubota dengan serial number D905 dan data manual mendapatkan hasil yang ditampilkan pada aplikasi dan website, maka dilakukan perhitungan margin of error adalah jumlah error saat melakukan pengambilan data. Margin of error sensor temperatur $=3.30 \%$. Margin of error data manual $=3.44 \%$. Dari hasil perhitungan tersebut, didapat margin of error sebesar $3.30 \%$ pada saat melakukan uji coba di engine Kubota serial number D905 dan dengan data manual mendapatkan hasil sebesar $3.44 \%$, jadi selisih antara dua pengujian adalah $0.14 \%$.

\section{Pengujian keseluruhan alat}

Pengujian ini dilakukan pada engine kubota dengan serial number D905. Secara garis besar sistem yang dirancang terdiri atas battery yang berfungsi sebagai energy listrik, sensor DS18B20 sebagai sensor yang berfungsi untuk memonitoring temperatur, ESP8266 sebagai penghubung jaringan internet dan arduino uno berfungsi sebagai mikrokontroller untuk mengolah data.

Pengujian ini dilakukan dengan menghubungkan sensor DS18B20 pada mikrokontroller melalui port bus 2 , port $5 \mathrm{v}$, dan ground lalu memberikan program pembacaan sensor DS18B20 dan menampilkan hasilnya pada thingspeak dan virtuino. Setelah itu meletakkan sensor pada cooling system engine seperti pada Gambar 5.

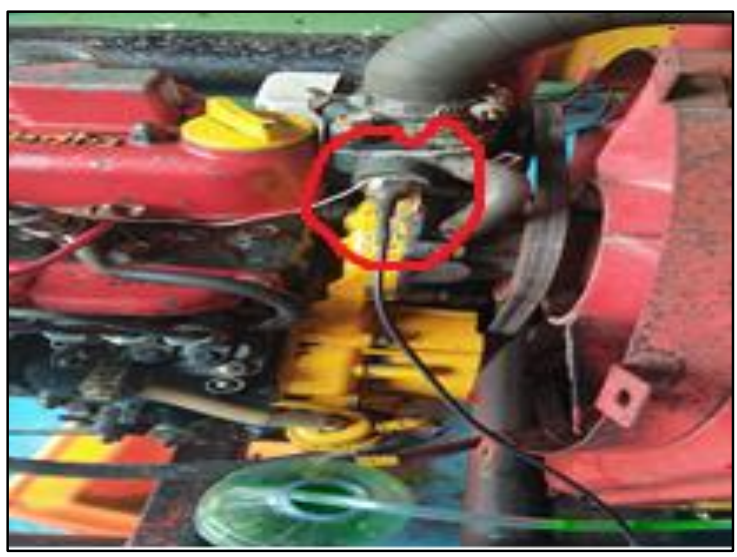

Gambar 5. Pengujian Alat

Pengujian dilakukan selama 1 jam temperatur engine tertinggi hanya mencapai $69^{\circ} \mathrm{C}$. Hasil dari pengujian dapat dilihat melalui internet dengan menggunakan website dan aplikasi android yang sudah terinstal di handphone.

\section{Pengujian keseluruhan alat}

Alat dapat bekerja sesuai dengan fungsinya, hal ini ditunjukkan dengan adanya perubahan temperatur pada saat pengujian. Hasil pembacaan sensor dapat dilihat melalui dua media yaitu mealui PC thingspeak dan aplikasi virtuino. Berikut hasil pembacaan yang telah ditampilkan (Gambar 6 dan Gambar 7). Hal ini semakna dengan penelitian terdahulu seperti [7]-[9]. Dalam penelitian Pasha (2016) tersebut hanya mampu menampilkan grafik pada thingspeak [7], adapun pada penelitian Darianian (2008) hanya mampu menampilkan tampilan suhu pada aplikasi mobile [9]. Namun pada penelitian ini dikembangkan dengan tambahan akses melalui aplikasi android yaitu aplikasi 
virtuino, untuk memudahkan dan lebih mobile dalam penggunaannya.

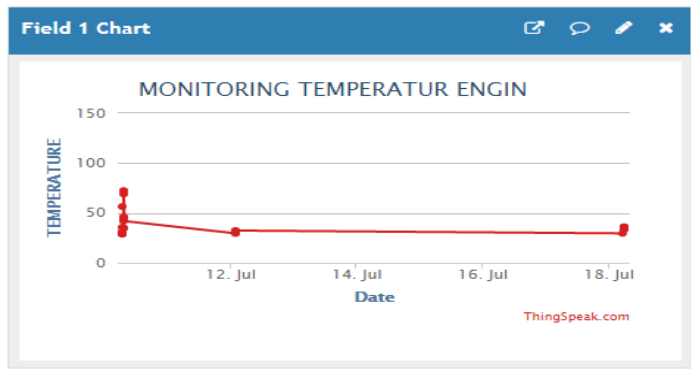

Gambar 6. Pembacaan Grafik pada Aplikasi thingspeak

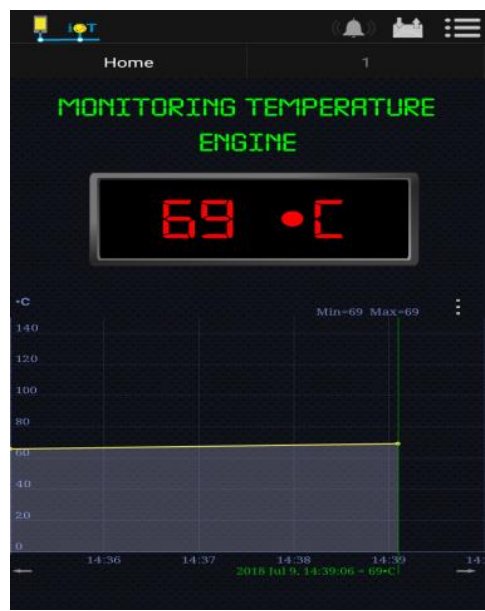

Gambar 7. Pembacaan Grafik pada Aplikasi Virtuino

\section{KESIMPULAN}

Alat monitoring temperatur engine berbasis internet of things telah dirancang dan dikembangkan dimana sistem terdiri dari arduino uno, sensor DS18B20, ESP8266, led dan buzzer. Pengujian alat menunjukkan adanya perbedaan selisih suhu antara alat yang dibuat dengan alat bantu thermometer gun dengan rata-rata sekitar $0,14^{\circ} \mathrm{C}$. Secara keseluruhan data suhu dapat dilihat dan diterima dengan baik melalui website thingspeak dan aplikasi android virtuino.

\section{REFERENSI}

[1]. Wicaksono, T.W., (2009). Analisa Pengaruh Resiko Repair dan
Maintenance Terhadap Kinerja Biaya Alat Berat Pada Proyek

Tambang. Tesis, Universtas Indonesia.

[2]. Tractor, U. (2017). Data Populasi Unit pada Cabang Tarakan Site Sesayap. Yayasan Karya Bakti United Tractors. Tarakan.

[3]. Sandrayanto, A. N., \& Mauladi, K. F. (2017). Sistem Pakar Diagnosa Overheating Pada Kendaraan Bersistem Pendingin Air (Liquid Cooling System ), Jurnal Teknika, 9(1), 1-5.

[4]. Missan, G. S., \& Keswani, I. P. (2016). Analysis of Causes of Engine Overheating due to Cooling System Failure Using Pareto Principle, International Journal of Engineering Trends and Technology (IJETT), 36(5), 242-248.

[5]. Karumbaya, A. (n.d.). IoT Empowered Real Time Environment Monitoring System, International Journal of Computer Applications, 129(5), 30-32.

[6]. Atzori, L., Iera, A., \& Morabito, G. (2010). The Internet of Things: A survey. Computer Networks, 54(15), 27872805.

[7]. Pasha, S. (2016). Thingspeak Based Sensing and Monitoring System for IoT with Matlab Analysis, International Journal of New Technology and Research (IJNTR) (6), 19-23.

[8]. Zanella, A., Member, S., Bui, N., Castellani, A., Vangelista, L., Member, S., \& Zorzi, M. 
(2014). Internet of Things for Smart Cities, IEEE Internet Of Things Journal 1(1), 2232.

[9]. Darianian, M., Michael, M. P., Communication, N. F., \& High, U. H. F. U. (2008). Smart Home Mobile RFIDbased Internet-Of-Things Systems and Services, International Conference on Advanced Computer Theory and Engineering, 8(1), 116120.

[10]. Susandi, D., Nugraha, W., \& Rodiyansyah, S. F. (2017). Perancangan Smart Parking System Pada Prototype Smart Office Berbasis Internet Of Things, Seminar Nasional Sains dan Teknologi, 1(2), 17.

[11]. Meng, Z., Wu, Z., Member, S., Muvianto, C., \& Gray, J. (2016). A Data-Oriented M2M Messaging Mechanism for Industrial IoT Applications, IEEE Internet of Things Journal 1(c), 1-11.

[12]. Lavanya, M., Muthukannan, P., Bhargav, Y. S. S., \& Suresh, V. (2016). Iot Based Automated Temperature and Humidity Monitoring and Control, Journal of Chemical and Pharmaceutical Science, 10(5), 86-88.

[13]. Rachman, F. Z. (2018). Sistem Pemantau Gas di Tempat Pembuangan Sampah Akhir Berbasis Internet of Things, Jurnal Teknologi dan Sistem Komputer, 6(3), 100-105.

[14]. Wicaksana, W. P. (2016). Simulasi Overheating Warning Alarm System Untuk Internal Combustion Engine. Seminar
Nasional Teknologi Informasi Dan Multimedia 2016, 1(2), 7-11. 